\title{
P 047 TISSUE DONATION AND END OF LIFE CARE
}

Rosemary Sedgwick, Natasha Gibson, Charles Williams, Lulu Kreeger, Grant Holmes. Kingston Hospital NHS Foundation Trust

10.1136/bmjspcare-2014-000654.88

Background NICE organ donation guidance makes it explicit in its first recommendation that 'organ donation should be considered as a usual part of "end-of-life care" planning.' The Liverpool Care Pathway (LCP) incorporated a prompt for clinicians to discuss tissue and organ donation with the patient, and if appropriate their relatives. A recent audit found that of 20 Kingston Hospital LCP proformas completed, only 1 had documented that this information had been ascertained.

Aims To explore junior doctors' attitudes surrounding discussion of tissue donation in the context of end of life care.

Methods We surveyed 33 junior doctors about their knowledge and attitudes towards tissue donation and end of life care, seeking to elucidate why the proforma question- "Does the patient have an expressed wish for tissue donation" was not being asked.

Results Fifty-two percent were not aware that there was a question about expressed wishes for tissue donation. Common reasons for not completing the question on the proforma included: "timing not feeling appropriate", "lack of familiarity with tissue donation procedure" and "unsure if patients on the LCP will be suitable". Views on the most appropriate time to discuss tissue donation were mixed: $45 \%$ said "A\&E registration" and $42 \%$ "as part of end of life discussions". Only 56\% of junior doctors reported having received any training on tissue donation.

Conclusions Junior doctors are undertrained and not comfortable discussing tissue donation as part of providing end of life care. Knowledge and communication skills pertaining to tissue donation should be incorporated into the foundation doctors' curriculum. Locally we plan to guarantee the implementation of teaching for all doctors about tissue donation and to add comprehensive information about the subject, including eligibility criteria and contact details for further guidance and support to the Kingston Hospital "junior doctor handbook". 